Ethiopian Journal of Environmental Studies \& Management 10(3): 351 - 360, 2017.

ISSN:1998-0507

doi: https://dx.doi.org/10.4314/ejesm.v10i3.6

Submitted: December 20, 2016

Accepted: April 19, 2017

\title{
A SPATIALLY BASED FIELD SPECIFIC CROP RECORDKEEPING SYSTEM PROTOTYPE FOR FARMERS
}

MAGAYA, A., *MARUZIVA, R., TOGAREPI, S. AND BUKA, L.T.

University of Zimbabwe, Department of Geoinformatics and Surveying

\begin{abstract}
The purpose of this study was to develop a spatially based application that is able to capture, query, update and maintain crop production historical records for each field. Maps of the farm showing the fields were made. The fields were then numbered. These spatial data were prepared using ArcGIS 9.3. A database was created in Microsoft Access 2007. The database contained information on crops, fertilizers and past management. The information was linked to the spatial data table and maintained in the database. An application was developed using Visual Basic 6 in Map Objects allowing for the manipulation of spatial data within the visual basic environment. Results have shown that a record keeping system may link crop records to respective mapped crop fields in a GIS environment. This was then used to view crop field area, update new field data in the non spatial database and query and display field data for a specified period of interest. New data were added to their respective tables whenever available.
\end{abstract}

Key Words: Recordkeeping system, Crop field, spatial, Farm, Management, Application

\section{Introduction}

Proper record keeping system is an essential element of a farm management system. The historical crop field data can be used for monitoring progress and identification of less productive fields which may need attention. Thorn Park Estate is a commercial farm owned by the University of Zimbabwe's Faculty of Agriculture. The farm is divided into three sections crop husbandry, research and teaching units, and animal husbandry. This research is centered on crop record keeping system at the farm because crop farming is the major, activity at the farm. As the years progress management have to depend on their memories when making decisions to modify their farming practices. But memories can be unreliable, particularly after a few days, months or years (Arzeno, 2004).

The major challenge is that currently there is no reliable record keeping for farming activities at the farm. Information about each crop field is not captured to monitor the performance of the field yearly. Field data needs to be captured for decision making and proper management. These include the inputs consumed, outputs, historical field data, and crop rotations made. As a result, analysis of trends in terms of production based on previous years cannot be carried

*Corresponding Author: Maruziva, R.

Email: maruziva@arts.uz.ac.zw 
out properly. This information may help the manager to identify under-performing fields and initiate corrective actions. It makes policy formulation and decision making quite difficult as relevant information is not available. In other words the farm lacks reliable and sufficient documentation of crop field operations data from planting to harvest.

Since farming is a business especially large scale, there is need to monitor field performance. A computerized spatially based record keeping system allows for the display of required field information. Documenting various crop practices on the farm may assist managers in identifying key strategies that they could use or a possible point where a problem would have occurred. Good records are important when making loan applications to expand the farming business (http://graduatefarmer.co.ke/2015/04/22/i mportance-of-keeping-farm-records/)

The first step in being a successful farm manager is keeping good, accurate records and establishing a sound recordkeeping system (James Hartsfield 2012). Record keeping is therefore the key to implementation of a successful crop management strategy on a yearly basis. In the face of the recent global economic crunch and the rapid pace of the farming industry, it is impossible for producers to manage a farm enterprise the way their parents did 30 years ago (Arzeno, 2004). Due to the problems aforementioned a spatially based record keeping system should be introduced for efficient information management to assist the farm managers to analyze annual trends in each field. Historical information about a specific field on nutrients, pesticide, crop rotation and crop yield can be displayed. Crop records allow managers to evaluate their farm productivity and to meet their farming goals.

Agricultural information management system by Hitachi Software Engineering, uses GIS technology to utilize and provide unified management of farm information about products, producers, yields, and quality. The relationship between cultivation records and parameters such as product yield and quality can be presented visually by incorporating functions such as management of production records to support the recording of past production information for use in checking the appropriateness of agricultural chemical use, growth analysis using satellite images, and fertilizer planning based on soil analysis results (Nishiguchi and Yamagata, 2009).

The increase in GIS and RS in the field of agriculture provide applications varying from Spatial Decision support system (SDSS), yield estimation, food and security analysis, Crop simulation models, Pest management, Livestock mapping, potential sites identification etc. are some of the most commonly used ones ( Sood et al., 2015 ).

An example of a related study is a research conducted at the South African Sugarcane Association Experiment Station. It focused on how sugarcane field records could be greatly improved by linking them to a Geographic Information System database, which allowed trends to be mapped and queries to be performed. Linking a Geographic Information System to a crop or irrigation model allowed simulation of crop yield and irrigation water use efficiency for each field, based on field information (Gers et al., 1999). Arcview GIS was 
linked to the IRRICANE crop model, which simulated cane yields for a north coast farm. Observed sugarcane yield and soils data of each field was used in ArcView to map temporal and spatial trends in production and soil chemical and nutritional status as well as to derive input data for the IRRICANE model. The research investigated only one crop cycle (sugarcane) and one irrigation strategy but this system will focus on a number of crops hence caters for rotations at the farm.

In the asbestos operation and maintenance for the Naval Air Engineering Station (NAES) in Lakehurst, New Jersey, a record keeping system that allow safety managers, tradespersons, and maintenance personnel crews to quickly locate, analyze, and update the appropriate information was developed (Seibert, 2011). A base map with roads, runways, hydrography, and buildings map layers was created in ArcView GIS to serve as the reference point for the asbestos management tasks. Asbestos survey information was then normalized and combined into a single database file. The database was then linked to the buildings on the map. On selecting a building on the map all the asbestos database records relating to that building would be highlighted. The application that was developed using both Visual Basic programming and Avenue Scripts would enable the managers to specify the building, floor plan, homogeneous area, or sample point they wished to access.

Interactive Property Tax Information System (PTIS) developed in India provided spatial query, visualisation, efficient updating and processing of property tax records. The information system incorporated the spatial and nonspatial details of the built up structures for effective maintenance, collection and updating of property tax information (Monoj Kumar et al., 2006).

- The study objective seeks to map the farm fields and record yearly operation on each of the fields for future analysis. A user friendly and database driven application that provides possibilities to query, visualize and update new season data without altering existing crop field information is developed. Some research questions that the system has to answer are; What is the total area currently under crop production?

- Can the system update new season data without altering existing data?

- Is the system able to query and display crop field historical data?

Decisions can now be made and underperforming fields can be identified and corrective measures taken to ensure productive farming.

\section{Study Area}

The study area was Thorn Park Estate (University of Zimbabwe farm) located $31^{\circ}$ East and $17^{\circ} 30^{\prime \prime}$ South, $18 \mathrm{~km}$ from the city of Harare along golden stairs road as in figure 1. The farm is in Natural region 1, which is an area of high yield potential. It lies in Mazowe District in Mashonaland Central Province. The highest point on the farm is 1480 metres above sea level with a fall of 60 metres to the lowest point. The terrain is flat with a slope of $2 \%$ or less and suitable for crop cultivation.

The soils are of deep to moderately deep well drained granular clay soils derived from epidiorite with some intrusions of banded ironstone. The area 
has a mean rainfall of about $815 \mathrm{~mm}$ for 50 years up to 1987 with a range of 444 $\mathrm{mm}$ to $1270 \mathrm{~mm}$. Most of rain is received between November and March. The mean monthly maximum temperature ranges from $22^{\circ} \mathrm{C}$ in June and July to $30^{\circ}$ $\mathrm{C}$ during the hot dry month of September to mid-November. (Kwela, 1998).

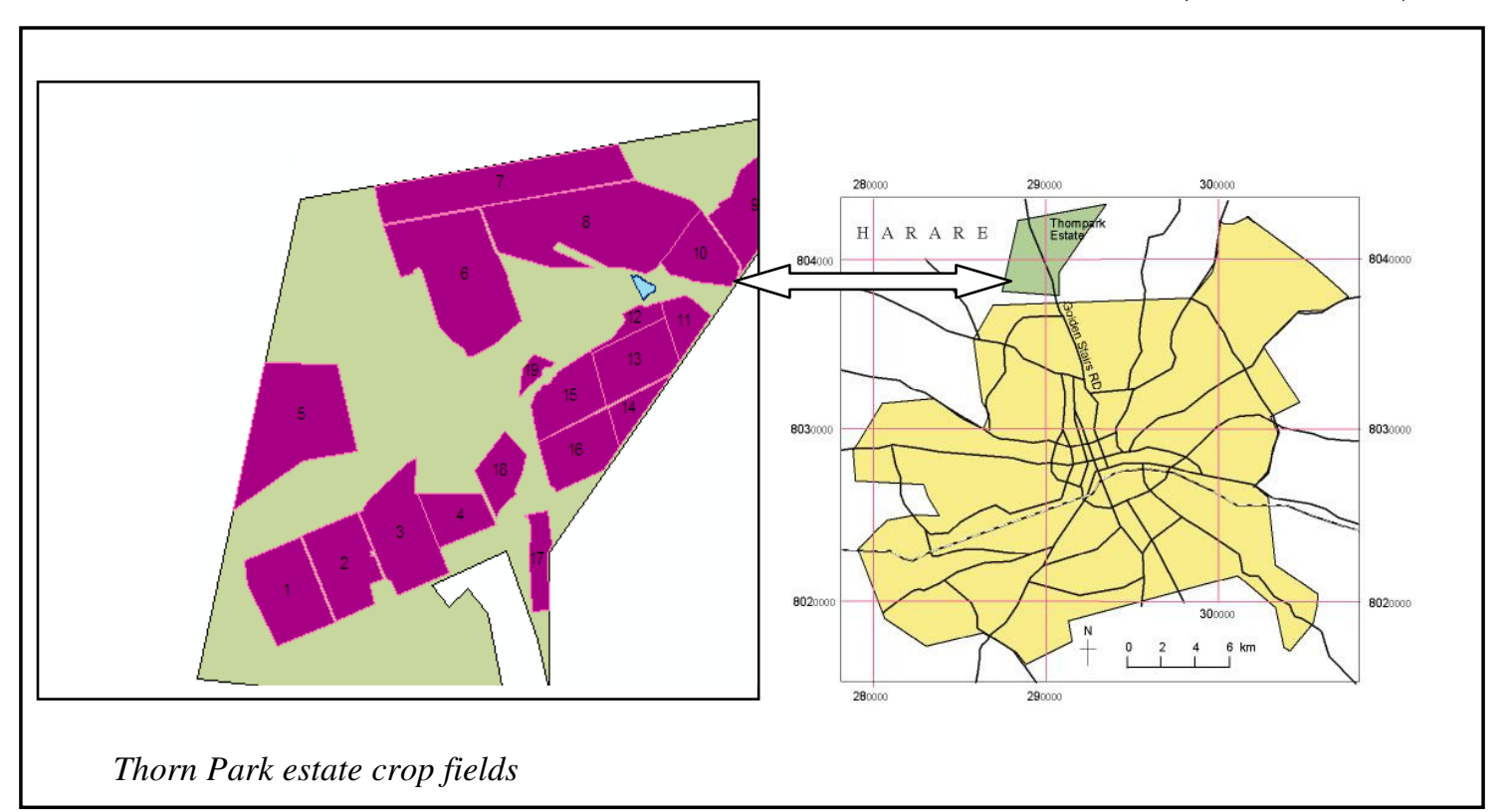

Figure 1: Location of study area

\section{Materials and Methods}

Identification of user requirements was a significant step in developing the record keeping system. Discussion with the would be users was carried out and the following requirements were identified;

A system that could be able to capture annual crop fields' details from planting up to harvesting.

Allows trends to be mapped, queries of each crop field to be performed and decisions on rotations and production be made using past information.

\section{Data Collection Spatial Data}

To obtain a digital map of the farm, scanned paper maps were georeferenced using survey diagrams from the Surveyor General's department because it's the legal document. The features that were digitized were; crop fields, roads, dam, boundaries and offices. The attributes assigned to the crop fields were; perimeter and area extent of each field, soil type i.e. clay, sand or loamy soil and field unique identifier, numbers 1 to 19 .

\section{Database Development and Data Population}

The tables for crops, fertilizers and pest management were created. These would capture crop field data for each farming season. The tables consisted of the following entities Crop table-: Seed, variety, planting date, Field_ID, total yield, yield_ha and date. Fertilizer table-: Name of fertilizer, date of application, rate of application, Field_ID and date

Pest management table-: Name of pest or disease, date of appearance, Field_ID, 
full name of chemical, crop sprayed, rate of application, spray machine and spray date. After creating the records tables, arbitrarily data was populated in them because there was no existing records.
The Field_ID was then used to link the tables to the crop fields. The tables would be maintained in a database and updated when need arise.

\section{Application Development}

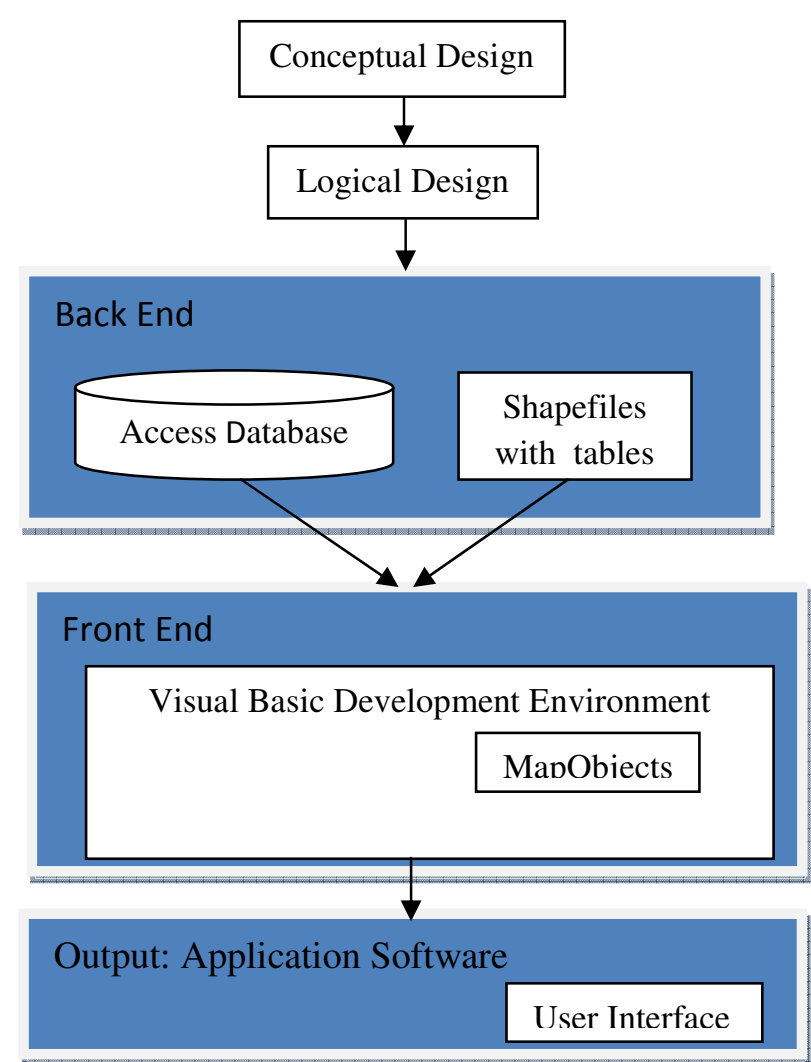

Figure 2: Application development

\section{Conceptual Design}

Conceptual design was divided into three items, the first one being identification of the users of the proposed system. Farm management staff was identified. The second stage was to look at the usage scenarios of the current system. No field specific crop record keeping system was in place. Lastly the usage scenarios of the proposed system which looked at how the management staff at the farm would be using the system when implemented.

\section{Logical Design}

Logical design involved the decisions made on software packages and tools to be used in the development of the system. Visual Basic 6.0 was chosen as the platform for development of the system incorporation of MapObjects 2.4 (Spatial) component. MapObjects provides powerful spatial and attribute filters to optimize performance. VB 6.0 
was chosen for the development of the application because of simplicity and ease of use. A pseudo password was chosen for the system as shown below

\section{Password Login}

Enter Password

Password =' thornpark'

Access Granted

\section{End Development}

In the Visual Basic environment the following forms were created; Login Form, Main Form, Record Maintenance Forms and Map Form.

Following the creation of shape files and the database, the actual application was developed using Visual basic 6.0 in MapObjects2.4. Visual Basic is the Microsoft's most admired application development tool used to develop windows based applications. Map Objects is an ActiveX component containing tools for customization and developing a GIS application. One of tools is the map control tool which allows for the addition of the map within the visual basic environment. A toolbar containing the following tools; zoom in, zoom out, pan, identify and full extent was added on the map form. These tools have their codes assigned to them.

After preparing the Map Form, other forms were then created, these include the Main Form. This is where the user selects an option to either view crop fields' history or add/edit records. It can only be accessed after entering the correct password in the Login Form.

There are two ways to initialize the MapObjects map control with data. You may either create a DataConnection object or use it to connect to a database to find GeoDataset objects, or you interactively select data through the map control's property sheet (ESRI, 1996).

\section{Testing}

System development is a challenging task since programming each instruction must be absolutely right or the whole program may fail to execute. The application was tested for cogency in various ways. System codes we tested by entering data for which the answer was known. For example, by entering the end date which is smaller than the start one. The result would show that end date cannot be smaller than start date. Other tests were also conducted to test for the validity of the system.

\section{Results and Discussion}

The objective of the study was to come up with a spatially based record system. The system records are linked to the map showing the fields. The area of each field was calculated by a field calculator in ArcGIS and the total area currently under production was found to be $7791812 \mathrm{~m}^{2}$ ( $\left.\approx 800 \mathrm{ha}\right)$.

\section{The Records}

Figure 3 shows the tables that capture crop field data for each season from planting to harvesting. These are all linked to the spatial data table and maintained in the database. New data are added to their respective tables whenever available. The data consists of the following 


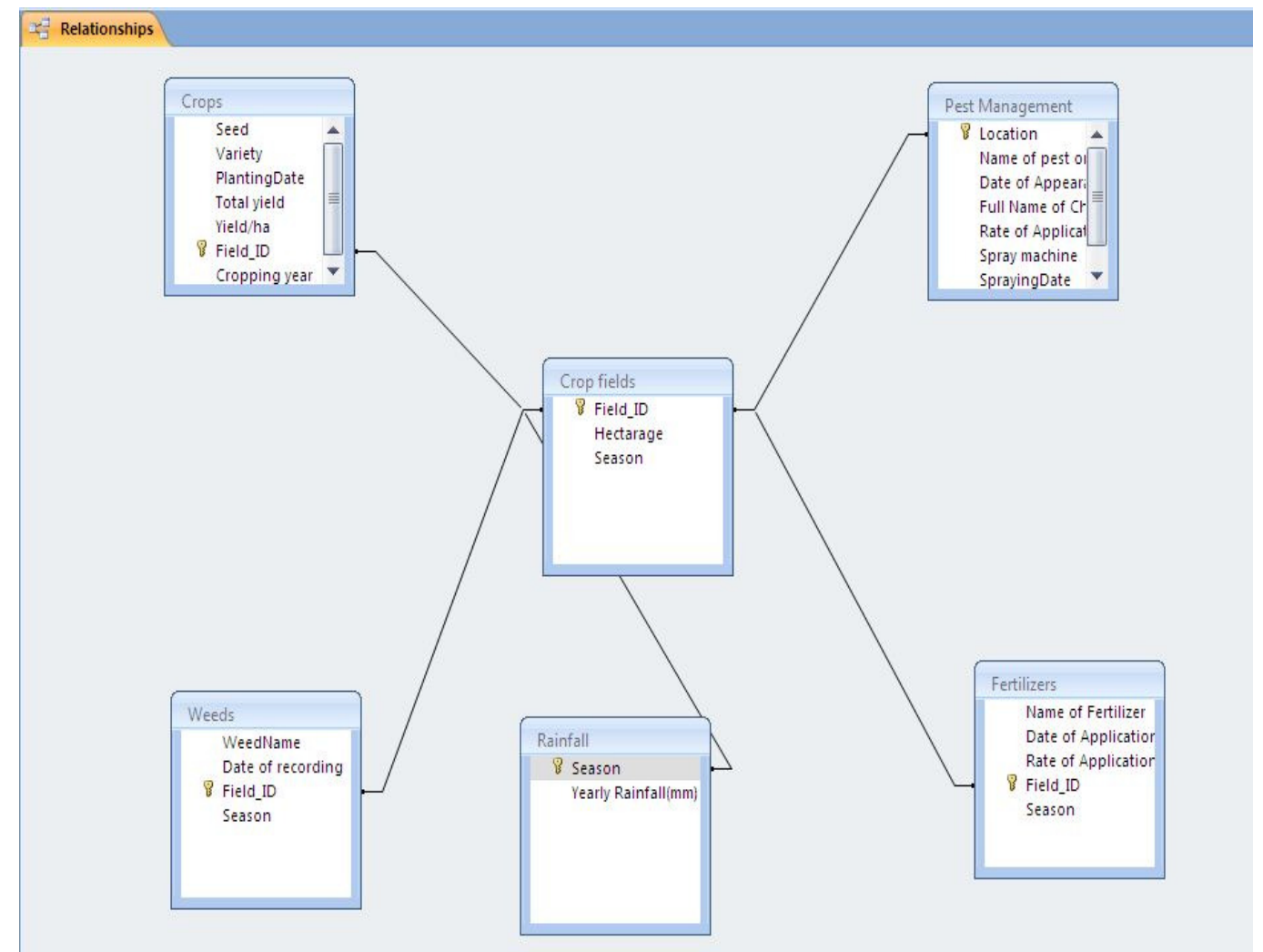

Figure 3: Table relationship

\section{The Application Interface}

The main form in figure 4 is the user interface that gives the options for viewing crop fields' history or record maintenance for adding new or edits existing records. It can only be accessed by authorized people after entering the correct password in the login form.

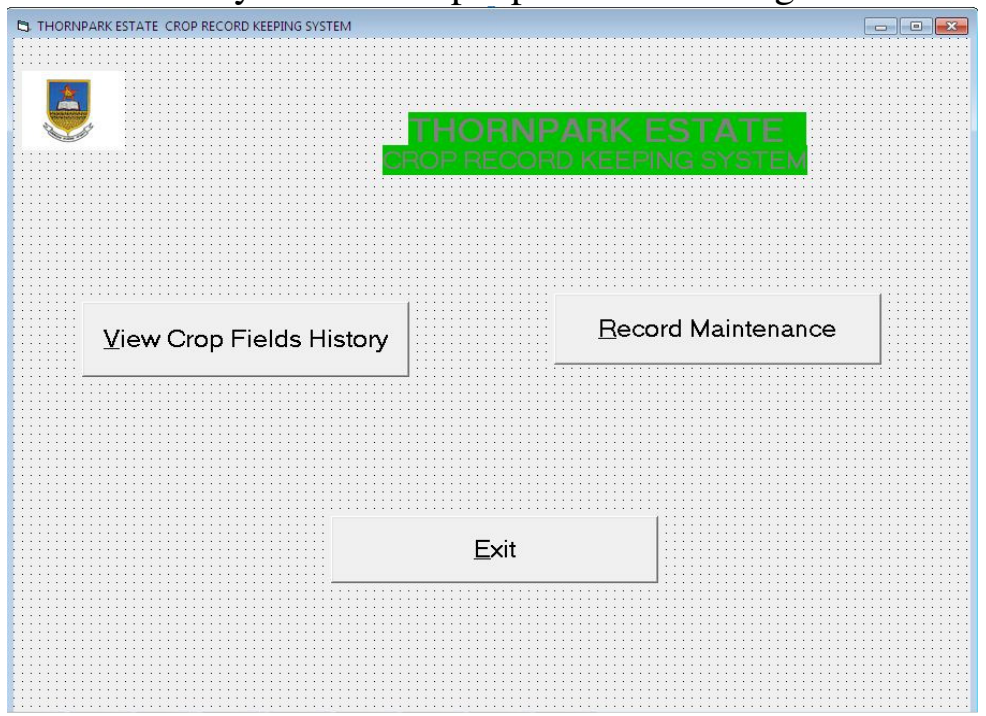

Figure 4: Application interface 


\section{Record Maintenance Option}

After login the user then chooses an option record maintenance on the main form and selects the data to update that is crop, fertilizer or pest management. In this case crop is chosen. Figure 5 shows on the right, possibilities that can be applied to the attributes that are shown on the left. Click on add new to enter the parameters and save the data. The application provides possibilities to update new season data without altering existing crop field information. This is done in order to maintain the history of the crop field.

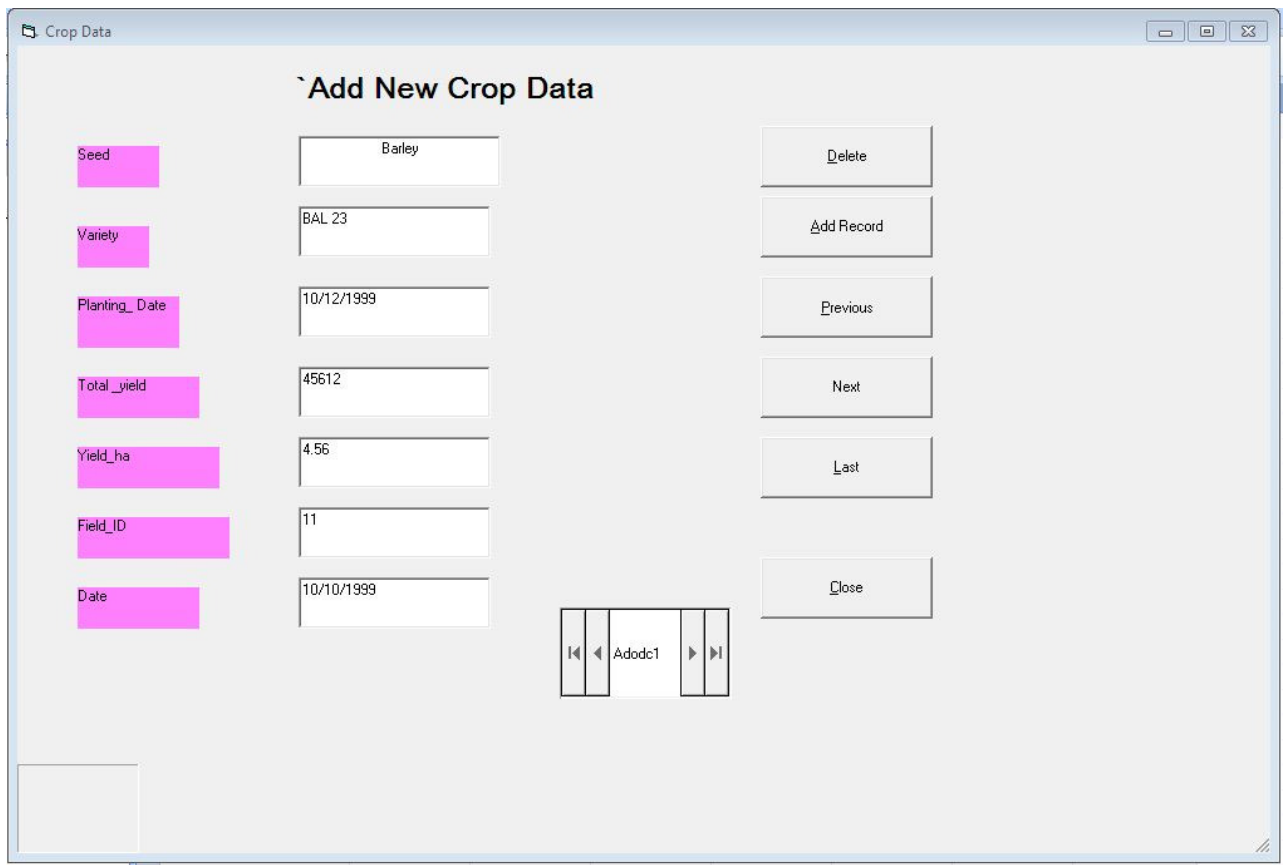

Figure 5: Add new or edit crop data form

\section{View Crop Fields History Option}

In order to query, display and visualize crop field data, a field number is selected; in this case 2 and period of interest entered is from 10/10/1999 to 10/10/2003. Crop field number 2 flashes on the map and the entire crop data between the specified years is displayed as shown on figure 6. This can also be done if the user wants to query about fertilizers or pest management data. The application therefore provides possibilities to query, display and visualize crop field historical data. It also proves that the spatial data and crop records are linked as shown by flashing field whose records are displayed. 


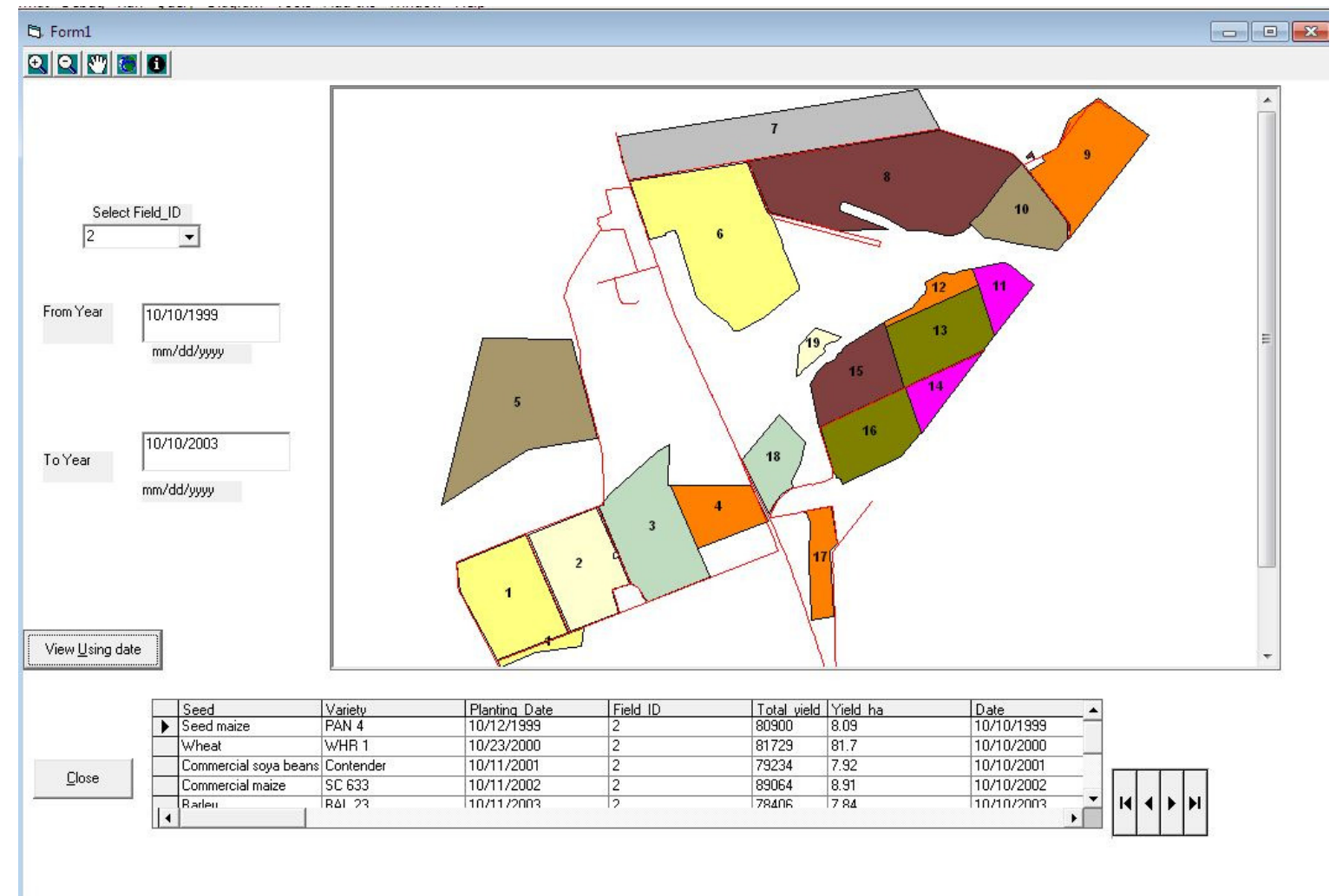

Figure 6: Crops table field number 2 data display

\section{Advantages of the System}

The system has a login form that allows access to authorized users only. Users are able to capture, edit and query both the spatial and attribute data. One strength is that when queried, the system will show data from both the spatial and attribute data together, indicating that they are related. The possibility to link farming data with the map files helps to identify the crop field being analyzed and the information about that particular field for a particular period of interest. The system is user friendly and information retrieval is done with ease, facilitating decision-making and farm management strategies.

\section{Limitations of the System}

However when entering new records the system should validate the entries and ensure that only valid data is accepted by the system. The system must be integrated to other farm system like the financial system, animal husbandry manpower etc.

\section{Conclusion}

However, the most important use of the system is to provide better crop field data management through the ability to integrate spatial and non spatial data. This application is able to capture, edit and query crop field data for any period of interest. It can assist farm management team and other relevant authorities in making informed decisions. The system is very simple, user friendly, provide quick access to data and all the systematic capabilities managers would require. Crop rotations can now be done 
A Spatially Based Field Specific Crop Recordkeeping System.................MAGAYA et al.

and underperforming fields can be identified and corrective measures taken to boost production at the farm. A stand alone spatially based system is cheap to maintain since it removes the need for the expensive GIS softwares but still performs the same functions as they do.

\section{Recommendations}

Since this was a prototype, further developments can still be done to it. The major recommendation would be to integrate all the farm information systems for efficient and effective farming practices. With resources in place a farm management information system can be designed that includes financial records, beef and dairy records and obviously crop production records. In trying to boost production other survey methods can be included such as Remote Sensing and Global Positioning System techniques. Extension of the project on a national scale and make it a Web based application to improve information management on farms.

\section{References}

Arzeno, A. (2004). Record keeping in farm management, College of Agriculture and Biological sciences, South Dakota State University.

Gers, C., Schmidt, E. and Bezutdenhout, C.N. (1999). Linking a Geographic Information System to farm records and crop models for field management.

http://www.sasta.co.za/wp-

content/uploads/... (Accessed $11 / 03 / 13)$

Hartsfield, J. (2012). The importance of keeping good farm records

Kwela, P. (1998). The University of Zimbabwe Farm guide for students, University of Zimbabwe publications

Sood, K., Singh, S., Rana, R.S. and Kaushal, A. (2015). Application of GIS in precision agriculture, South Dakota State University.

Monoj Kumar, R., Sadish, R., Anandan, P.S. and Venkatesh, G. (2006). Property tax information system using mapobjects

Osamu Nishiguchi, O. and Yamagata, N. (2009). Agricultural Information Management System Using GIS Technology

Seibert, S.L. (2011). What is GIS: U.S Department of Health \& Human Services http://www.hhs.gov (Accessed 13/04/13)

VisualBasic6 (VB6)-Setting up the ADO Data Control http://www. visualbasic.features.com/learn-vb6advanced/less

(Accessed 26/04/13)

http://graduatefarmer.co.ke/2015/04/22/i mportance-of-keeping-farmrecords/ 